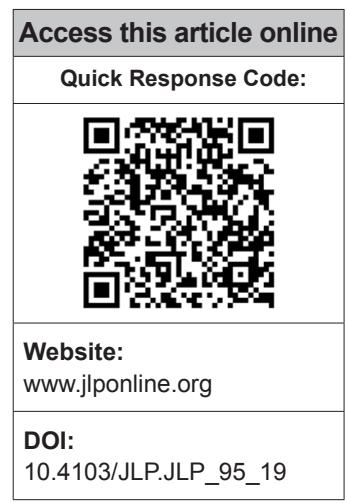

Department of Microbiology, Pondicherry Institute of Medical Sciences, Puducherry, India

Address for correspondence:

Dr. S. R. Ramya, Associate Professor, Department of Microbiology, Pondicherry Institute of Medical Sciences,

Puducherry, India. E-mail: ramyasr121186@ gmail.com

Submission: 29-05-2019 Accepted: 23-08-2019

\title{
Association of ABO blood groups with dengue fever and its complications in a tertiary care hospital
}

\author{
Shivani Ravichandran, S. R. Ramya, Reba Kanungo
}

\section{Abstract:}

CONTEXT: Dengue fever (DF) has been steadily increasing in India with outbreaks in certain areas taking the proportion of epidemics. Along with secondary dengue, several risk factors predispose to dengue hemorrhagic fever and dengue shock syndrome. Very few studies associating the relationship between dengue and its severity with $\mathrm{ABO}$ blood group have been documented.

AIMS: The aim of this study was to determine the association between distribution of $A B O \mathrm{Rh}$ blood groups and DF and DF with thrombocytopenia.

SETTINGS AND DESIGN: This was a retrospective descriptive study conducted the clinical laboratory of the department of microbiology.

MATERIALS AND METHODS: Dengue patients whose case record contained information on blood group were screened for details of blood group and confirmed dengue diagnosis. Randomly 384 case records were selected. These were divided into two groups; Group 1 included DF cases (platelet count $>20,000$ ) and Group 2 included DF cases with thrombocytopenia (platelet count $<20,000$ ). Control group consisted of patients other than dengue, whose blood grouping had been done; randomly 390 were selected and analyzed.

STATISTICAL ANALYSIS USED: $P$ value was calculated using the Chi-square test. Odds ratio were calculated using the Fisher's exact test.

RESULTS: DF was higher in $23 \%$ of individuals with $A B$ blood group as compared to $8.5 \%$ of controls $(P=0.0004)$, whereas patients with blood group $O$ were significantly less affected with DF $(P=0.0048)$. Disease severity was not associated with any of the blood groups.

CONCLUSIONS: Individuals with AB blood group are more prone to DF, whereas individuals with blood group $\mathrm{O}$ are less prone.

Key words:

$A B O$ blood group, dengue fever, platelet count

\section{Introduction}

Dengue fever (DF) is endemic in more than 100 countries, with most cases reported from the American, Southeast Asian, and Western Pacific regions of WHO. Dengue is endemic in almost all states in India and is the leading cause of hospitalization..$^{[1]}$ It has been estimated that there would be 390 million dengue

This is an open access journal, and articles are distributed under the terms of the Creative Commons Attribution-NonCommercial-ShareAlike 4.0 License, which allows others to remix, tweak, and build upon the work non-commercially, as long as appropriate credit is given and the new creations are licensed under the identical terms.

For reprints contact: reprints@medknow.com infections per year $(95 \%$ credible interval: 284-528 million), of which 96 million (67-136 million) manifest clinically (with any severity of disease). ${ }^{[2]}$ In 2017, India has recorded 188,401 dengue cases and 325 deaths. There is a sudden upsurge of dengue cases in the Union territory of Puducherry, from 490 (2016) to 4568 and seven deaths in 2017. ${ }^{[3]}$ DF may result in complications such as dengue hemorrhagic fever (DHF) and dengue shock syndrome (DSS). ${ }^{[4]}$ Coinfection with more than one serotype of dengue

How to cite this article: Ravichandran S, Ramya SR, Kanungo R. Association of ABO blood groups with dengue fever and its complications in a tertiary care hospital. J Lab Physicians 2019;11:265-9. 
virus (DENV) is attributed to increased incidence of complications. ${ }^{[5]}$

The predisposition to DHF or DSS is determined by human leukocyte antigen (HLA) haplotype which has been proposed by several researchers; no clear, specific polymorphisms have been unequivocally described. ${ }^{[6]}$ The ABO blood group is part of innate immunity, and it has been described that individuals with different $A B O$ blood groups differ in their susceptibility or resistance to viral and bacterial infections and diseases. ${ }^{[7,8]} \mathrm{A}$ relationship between blood groups and disease was first hypothesized by Kaipainen and Vuorinen during $1960,{ }^{[9]}$ and the gene involved in ABO blood groups was discovered in 1990. ${ }^{[7]}$ The ABO blood group plays a considerable role in making a person susceptible or resistant to diseases such as malaria ${ }_{1}^{[10]}$ cholera, ${ }^{[11]}$ Helicobacter pylori, ${ }^{[12]}$ and chikungunya ${ }^{[13]}$ infections.

A study conducted by Kalayanarooj et al. found that blood group $\mathrm{AB}$ was associated with more severe dengue disease with dengue serotypes 2 , 3, and 4 than with dengue serotype $1 .{ }^{[14]}$ A study conducted in Karnataka observed that dengue infections were higher in individuals with O-positive blood group (42.8\%) when compared with controls (32\%). ${ }^{[15]}$

However, there are few studies globally including India regarding the association of $\mathrm{ABO}$ blood group, dengue disease, and its severity, predicting the outcome of DENV infection. Using the ABO blood group, data may have a clinical and financial implication for management of patients. The present study was designed to determine the association between distribution of $\mathrm{ABO}$ Rh blood groups and DF and DF with thrombocytopenia.

\section{Materials and Methods}

This was a retrospective descriptive study conducted during May-June 2018 in the department of microbiology. The study was reviewed and approved by the institute research and ethics committees. A waiver of consent was sought and granted.

Case records of patients who tested positive for dengue NS1 antigen/dengue immunoglobulin M (IgM) antibodies/both with information on blood group were included in the study. A calculated sample size of 384 was included in the study based on prevalence rate of $47.7 \%$ (2017 outbreak), 5\% precision, and 95\% confidence interval. The study population was divided into two groups. Group 1 included DF cases (platelet count $>20,000$ ), whereas Group 2 included DF cases with thrombocytopenia (platelet count $<20,000$ ). Control group consisted of patients in whom dengue had been excluded from January 2017 to December 2017 and whose blood grouping was done. Of these, 390 were randomly selected by simple random sampling.

After screening the case records for inclusion criteria, 384 records were randomly selected by simple random sampling (Research Randomizer [https://www. randomizer.org/]). A detailed pro forma including the demographic details; clinical features including duration of fever and presence of rash; comorbidities such as diabetes, hypertension, bleeding manifestation, if any; and presence of acute respiratory distress syndrome (ARDS) was used. Vitals such as blood pressure and pulse rate and laboratory parameters such as serum glutamic-oxaloacetic transaminase (SGOT), serum glutamic-pyruvic transaminase (SGPT), hemoglobin, mean corpuscular volume (MCV), total leukocyte count, and platelet count were noted. Patient outcome was also recorded. All details were entered in Microsoft Excel, and the data was analyzed.

\section{Statistical analysis}

All continuous data are presented as mean \pm standard deviation and categorical data as percentiles. Data were analyzed using IBM SPSS Statistics for Windows, version 22.0. IBM Corp., Armonk, NY, USA. DF and DF with thrombocytopenia were compared using the Chi-square test. Odds ratio were calculated using the Fisher's exact test to test for the strength of association between risk factors. $P<0.05$ was considered as significant.

\section{Results}

Out of the 384 cases, 118 were blood group B, 90 were blood group $\mathrm{AB}$ and 88 were each of blood group $\mathrm{A}$ and $\mathrm{O}$ [Figure 1]. The frequency of blood group among the control group is represented in Figure 1.

It was observed that dengue infections were higher in individuals with $\mathrm{AB}$ blood group (23\%) when compared with controls $(8.5 \%), P=0.0004$. Blood group $\mathrm{O}$ considerably less affected with DF had $P=0.0048$ [Table 1].

Dengue cases were more in males compared to females. It was more among the age group of 21-30 years. Dengue NS1 antigen was positive in 248 cases, IgM positive in 27 cases, and both positive in 109 cases [Table 2]. Laboratory parameters are represented in Table 3 . There was no significant difference in these parameters among different blood groups.

Bleeding manifestations were seen in 14 cases (blood group: A positive -2 cases, $B$ positive -7 , AB positive -2 , and $\mathrm{O}$ positive -3 ). ARDS was seen in 3 cases (blood group A -2 cases and B -1 case). Five of the patients 


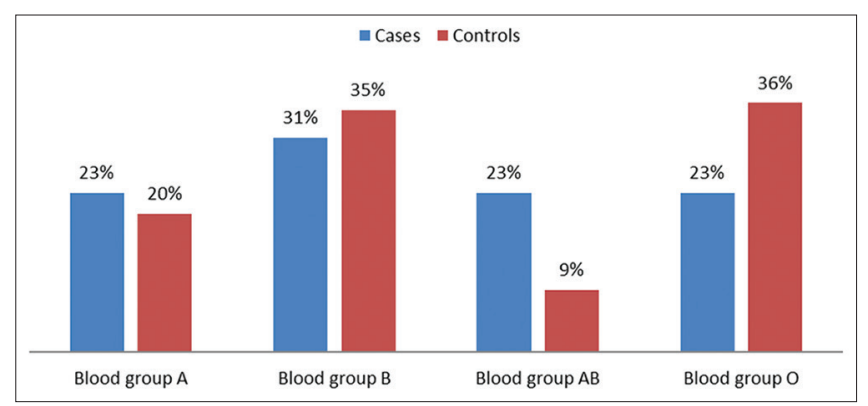

Figure 1: Distribution of $A B O$ blood group among dengue cases and controls

Table 1: Frequency of ABO blood group among dengue cases and controls

\begin{tabular}{l|c|c|c|c|c}
\hline Blood group & Cases & Controls & $\boldsymbol{P}$ & OR & $95 \% \mathrm{Cl}$ \\
\hline $\mathrm{A}$ & 88 & 79 & & & \\
$\mathrm{~B}$ & 118 & 137 & 0.197 & 1.2933 & $0.8748-1.9121$ \\
$\mathrm{AB}$ & 90 & 33 & 0.0004 & 0.4084 & $0.2474-0.6743$ \\
$\mathrm{O}$ & 88 & 141 & 0.0048 & 1.7848 & $1.1917-2.6732$ \\
\hline
\end{tabular}

Chi-square test was used to compare the cases and controls. $P<0.05$

considered as significant. $\mathrm{OR}=\mathrm{Odds}$ ratio, $\mathrm{Cl}=$ Confidence interval

Table 2: Demographic details, serology, and comorbidities of dengue cases

\begin{tabular}{lc|c|c|c|c}
\hline Blood group & A & B & AB & O & Total \\
\hline Gender & & & & & \\
$\quad$ Male & 48 & 73 & 51 & 53 & 225 \\
$\quad$ Female & 40 & 45 & 39 & 35 & 159 \\
$\begin{array}{l}\text { Age group (years) } \\
\quad 10\end{array}$ & 11 & 6 & 13 & 8 & 38 \\
$11-20$ & 23 & 23 & 21 & 19 & 86 \\
$21-30$ & 19 & 39 & 23 & 21 & 102 \\
$31-40$ & 21 & 28 & 11 & 16 & 76 \\
$41-50$ & 7 & 10 & 12 & 13 & 42 \\
$51-60$ & 3 & 7 & 7 & 8 & 25 \\
$>61$ & 4 & 5 & 3 & 3 & 15 \\
Serology - ELISA & & & & & \\
$\quad$ NS1 Ag positive & 56 & 74 & 63 & 55 & 248 \\
IgM positive & 7 & 7 & 6 & 7 & 27 \\
Both NS1 and IgM positive & 25 & 37 & 21 & 26 & 109 \\
Comorbidities & & & & & \\
DM & 8 & 7 & 5 & 8 & 28 \\
HTN & 4 & 3 & 2 & 4 & 13 \\
\hline
\end{tabular}

HTN=Hypertension, DM=Diabetes mellitus, NS1=Non structural protein 1 went against medical advice, and 379 patients improved and were discharged.

The distribution of each blood group among patients with DF was similar to that among patients with DF with thrombocytopenia (platelet count $<20,000$ ). In dengue virus infections, all four blood groups and $\mathrm{Rh}$ had similar susceptibility to severe disease, that is, no association between blood group and disease severity was seen [Table 4].

\section{Discussion}

Dengue is an endemic disease which is associated with morbidity and mortality. DHF and DSS are the complications in secondary DF. There are many predisposing factors which are allied with dengue, one of which could be blood group. Blood group antigens help in determining the susceptibility to infections. ${ }^{[6,8]}$

The present study suggests that blood group $A B$ is associated with dengue disease when compared to the control group and was statistically significant, which was in concordance with the results of the study by Kalayanarooj et al., wherein blood group $\mathrm{AB}$ was a risk factor predisposing for severe dengue disease.$^{[14]}$ Blood group distribution in controls was consistent with those in the general South Indian population. ${ }^{[15]}$ The distribution of each blood group among patients with DF was similar to that among patients with DF with thrombocytopenia (platelet count $<20,000$ ). In dengue virus infections, all four blood groups and $\mathrm{Rh}$ had similar susceptibility to severe disease, that is, no association between blood group and disease severity was seen.

On the other hand, in the current study, patients with blood group $\mathrm{O}$ were considerably less affected with DF (statistically significant); in contrast, a study by Khode et al. suggested that blood group $\mathrm{O}$ is possibly a risk factor predisposing for dengue disease. ${ }^{[16]}$

In the current study, there was an association between $\mathrm{AB}$ blood group and DF but no association between

Table 3: Laboratory parameters of dengue cases

\begin{tabular}{|c|c|c|c|c|c|c|}
\hline Blood group & SGOT & SGPT & $\begin{array}{c}\text { Hemoglobin } \\
(\mathrm{g} / \mathrm{mL})\end{array}$ & MCV & $\begin{array}{c}\text { Total leukocyte count } \times 1000 \\
\text { cubic } \mathrm{mm}\end{array}$ & Platelet count $\times 1000$ \\
\hline \multicolumn{7}{|l|}{$\bar{A}$} \\
\hline Mean \pm SD & $138.51 \pm 165.905$ & $78.27 \pm 83.770$ & $12.955 \pm 2.0452$ & $81.90 \pm 7.738$ & $5.473 \pm 2.7252$ & $72.20 \pm 53.595$ \\
\hline \multicolumn{7}{|l|}{ B } \\
\hline Mean \pm SD & $157.27 \pm 156.052$ & $86.86 \pm 80.632$ & $13.286 \pm 1.9528$ & $82.88 \pm 7.631$ & $5.140 \pm 2.8552$ & $60.58 \pm 56.659$ \\
\hline \multicolumn{7}{|l|}{$\mathrm{AB}$} \\
\hline Mean \pm SD & $102.97 \pm 122.362$ & $67.43 \pm 121.777$ & $13.189 \pm 2.1427$ & $83.61 \pm 6.980$ & $5.166 \pm 2.8050$ & $85.07 \pm 68.543$ \\
\hline \multicolumn{7}{|l|}{$\mathrm{O}$} \\
\hline Mean \pm SD & $147.66 \pm 222.219$ & $86.72 \pm 120.517$ & $13.024 \pm 2.0986$ & $83.42 \pm 8.222$ & $4.929 \pm 2.3860$ & $70.41 \pm 77.552$ \\
\hline
\end{tabular}


Table 4: Distribution of $\mathrm{ABO}$ and $\mathrm{Rh}$ blood groups in dengue fever without and with thrombocytopenia

\begin{tabular}{lccccc}
\hline $\begin{array}{l}\text { Blood } \\
\text { group }\end{array}$ & $\begin{array}{c}\text { Group 1: } \\
\text { Platelet } \\
\text { count } \\
>20,000\end{array}$ & $\begin{array}{c}\text { Group 2: } \\
\text { Platelet } \\
\text { count } \\
<20,000\end{array}$ & $P$ & OR & $95 \% \mathrm{Cl}$ \\
\hline A positive & 70 & 16 & & \\
A negative & 2 & 0 & 0.92030 .8545 & $0.0391-18.6563$ \\
B positive & 81 & 33 & & \\
B negative & 4 & 0 & 0.35270 .2703 & $0.0142-5.1613$ \\
AB positive & 78 & 11 & & \\
AB negative & 1 & 0 & 0.61172 .2754 & $0.0874-59.269$ \\
O positive & 67 & 17 & & \\
O negative & 2 & 2 & 0.15753 .9412 & $0.5171-30.038$ \\
\hline
\end{tabular}

Chi-square test was used to compare the two groups: Dengue fever with platelet count $>20,000$ and Dengue fever with platelet count $<20,000$. $P<0.05$ considered as significant. $\mathrm{OR}=\mathrm{Odds}$ ratio, $\mathrm{Cl}=\mathrm{Confidence}$ interval

AB blood group and DHF. A short communication by Murugananthan et al. reported that a significantly higher proportion of patients with $\mathrm{AB}$ blood group had DF and DHF when compared to the general population. ${ }^{[17]}$

Majority of dengue-positive cases in the present study were blood group B individuals which is in agreement with the observations made by Bulugahapitiya and Satarasinghe. ${ }^{[18]}$ but not statistically significant when compared to the control group.

The innate immune system consisting of natural killer cells, dendritic and mast cells, macrophages, natural antibody-producing B-cells, the complement system, and host genetic factors plays a role in elimination of viral infections. ${ }^{[19]}$ Among these innate factors, a predilection for an individual to be susceptible or resistant to phenotypes of infectious diseases and their clinical manifestations resides in host genetic factors. Two genetic factors (HLA and ABO blood groups) have, to some extent, been demonstrated to play an imperative role in resistance or susceptibility to infectious diseases. ${ }^{[7]}$

The blood group antigens are carbohydrate in nature; the immunodominant sugar in case of A determinant is $\mathrm{N}$-acetyl-d-galactosamine, and for B determinant, it is d-galactose. Galactosyltransferases are involved in the synthesis of these carbohydrates. ${ }^{[7]}$ The antibody that recognizes these carbohydrates is mainly natural IgM. ${ }^{[20]}$ IgM antibodies produced against glycosylated dengue viral proteins, in patients with DENV infection, have been shown to cross-react with host cells. Consequently, whether the combination of $\mathrm{ABO}$ blood group and the level of natural IgM antibody circulating in individuals has an effect on dengue disease needs to be explored. The study was limited by its retrospective case record-based design where several parameters could not be explored.

A correlation between HLA and dengue disease has been reported, but no specific polymorphisms have been found to be unambiguously associated with disease severity. ${ }^{[6]} \mathrm{It}$, therefore, is of interest to see whether there is any correlation between a polymorphism in the galactosyltransferase gene and dengue disease severity. Stephens et al. studied the association of HLA and dengue-virus infection and found that the infecting viral serotype influenced the strength of the association between specific HLA alleles and dengue disease severity. ${ }^{[21]}$

\section{Conclusions}

This study concludes that $A B$ blood group is associated with a higher risk of developing DF than those with other blood groups. While patients with blood group $\mathrm{O}$ were significantly at a lower risk of developing DF compared to the general population. There is no association between blood group and disease severity as patients of all four blood groups and Rh had similar susceptibility to severity of the disease. Further studies are needed to determine whether dengue serotype, HLA, and $\mathrm{ABO}$ are independent variables and whether some blood subgroups are associated with a particularly high risk of DENV infection.

\section{Acknowledgment}

We would like to thank Indian Council of Medical Research - Short Term Studentship (ICMR STS) Program (Reference ID - 2018-00410).

\section{Financial support and sponsorship}

This study was financially supported by ICMR STS.

\section{Conflicts of interest}

There are no conflicts of interest.

\section{References}

1. Ganeshkumar P, Murhekar MV, Poornima V, Saravanakumar V, Sukumaran K, Anandaselvasankar A, et al. Dengue infection in India: A systematic review and meta-analysis. PLoS Negl Trop Dis 2018;12:e0006618.

2. Bhatt S, Gething PW, Brady OJ, Messina JP, Farlow AW, Moyes CL, et al. The global distribution and burden of dengue. Nature 2013;496:504-7.

3. National Vector Borne Disease Control Programme. Available from: http://www.nvbdcp.gov.in/den-cd.html. [Last accessed on 2018 Oct 02].

4. Burke DS, Monath TP. Flaviviruses. In: Knipe DM, Howley PM, editors. Fields Virology. $4^{\text {th }}$ ed. Philadelphia, (PA): Lippincott Williams and Wilkins; 2001. p. 1043-126.

5. dos Santos CL, Bastos MA, Sallum MA, Rocco IM. Molecular characterization of dengue viruses type 1 and 2 isolated from a concurrent human infection. Rev Inst Med Trop Sao Paulo 2003;45:11-6.

6. Stephenson JR. The problem with dengue. Trans R Soc Trop Med Hyg 2005;99:643-6.

7. Greenwell P. Blood group antigens: Molecules seeking a function? Glycoconj J 1997;14:159-73. 
8. Skripal' IG. ABO system of blood groups in people and their resistance to certain infectious diseases (prognosis). Mikrobiol Z 1996;58:102-8.

9. Kaipainen WJ, Vuorinen YV. ABO blood groups in pernicious anaemia and pernicious tapeworm anaemia. Ann Med Exp Biol Fenn 1960;38:212-3.

10. Fry AE, Griffiths MJ, Auburn S, Diakite M, Forton JT, Green A, et al. Common variation in the $\mathrm{ABO}$ glycosyltransferase is associated with susceptibility to severe plasmodium falciparum malaria. Hum Mol Genet 2008;17:567-76.

11. Harris JB, Khan AI, LaRocque RC, Dorer DJ, Chowdhury F, Faruque AS, et al. Blood group, immunity, and risk of infection with vibrio cholerae in an area of endemicity. Infect Immun 2005;73:7422-7.

12. Jaff MS. Relation between $\mathrm{ABO}$ blood groups and Helicobacter pylori infection in symptomatic patients. Clin Exp Gastroenterol 2011;4:221-6.

13. Lokireddy S, Sarojamma V, Ramakrishna V. Genetic predisposition to chikungunya - A blood group study in chikungunya affected families. Virol J 2009;6:77.

14. Kalayanarooj S, Gibbons RV, Vaughn D, Green S, Nisalak A, Jarman RG, et al. Blood group $A B$ is associated with increased risk for severe dengue disease in secondary infections. J Infect Dis 2007;195:1014-7.
15. Periyavan S, Sangeetha SK, Marimuthu P, Manjunath BK, Seema DM. Distribution of ABO and rhesus-D blood groups in and around Bangalore. Asian J Transfus Sci 2010;4:41.

16. Khode V, Kabbin G, Ruikar K. Association of ABO Rh blood group with dengue fever and dengue hemorrhagic fever: A case-control study. J Appl Hematol 2013;4:145-8.

17. Murugananthan K, Subramaniyam S, Kumanan $T$, Owens L, Ketheesan N, Noordeen F. Blood group AB is associated with severe forms of dengue virus infection. Virusdisease 2018;29:103-5.

18. Bulugahapitiya DU, Satarasinghe RL. Preponderance of blood group B among dengue fever patients with serious complications in a tertiary care hospital. Ceylon Med J 2003;48:95-6.

19. Parkin J, Cohen B. An overview of the immune system. Lancet 2001;357:1777-89.

20. Chambers TJ, Hahn CS, Galler R, Rice CM. Flavivirus genome organization, expression, and replication. Annu Rev Microbiol 1990;44:649-88.

21. Stephens HA, Klaythong R, Sirikong M, Vaughn DW, Green S, Kalayanarooj S, et al. HLA-A and-B allele associations with secondary dengue virus infections correlate with disease severity and the infecting viral serotype in ethnic Thais. Tissue Antigens 2002;60:309-18. 